\title{
Contributing Factors to Medication Errors Among Nurses in Iran: A Systematic Review
}

\author{
Amir Mirsadeghi ${ }^{{ }^{*}}$, Iman Jafari Iraqi ${ }^{1}$, Mohsen Mollahadi ${ }^{1}$ \\ ${ }^{1}$ Faculty of Nursing, Baqiyatallah University of Medical Sciences, Tehran, Iran
}

Corresponding Author: Amir Mirsadeghi, Faculty of Nursing, Baqiyatallah University of Medical Sciences, Tehran, Iran. Tel: +989125801963, Email: amir.mirsadeghi66@gmail.com

Received July 8, 2019; Accepted August 29, 2019; Online Published September 28, 2019

\begin{abstract}
Introduction: Medication errors have been one of the oldest and most common errors of nursing profession. Although, most medication errors do not lead to serious harm to patients, some of them could be important and has financial pressure to the healthcare system. This study was conducted to determine contributing factor of medication errors among nurses in Iran.

Methods: This was a systematic review study that was conducted through Cochrane seven-stage model. Persian articles databases including Iran Medex, SID, Irandoc, Magiran and Google Scholar were reviewed, using keywords Including medication errors, Iran and nursing. The study was conducted during 2003 to 2016.

Results: At first, 85 studies were reviewed, then 41 of them were excluded based on the exclusion criteria. Finally, 35 papers and 9 abstracts of seminars were analyzed. The results were extracted in three contributing factors including personal factors, organizational factors, and personal and organizational factors.

Conclusion: The results of the present review indicated that, no factors can result in medication error separately. Most medication errors result from multiple and interactive factors. As individual factors are unavoidable in medication errors, it should be emphasized on managing organizational factors and developing teaching programs in order to prevent or reduce medication errors.

Keywords: Medication Errors, Nursing, Iran

Citation: Mirsadeghi A, Jafari Iraqi I, Mollahadi M. Contributing factors to medication errors among nurses in Iran: a systematic review. Int J Med Rev. 2019;6(3):105-112. doi:10.29252/ijmr-060307.
\end{abstract}

\section{Introduction}

Patient safety is an important priority in the healthcare systems which aim to prevent medical errors before leading, harm, injury or death to patients. ${ }^{1}$ safety and risk management are referred to minimizing the risks at the acceptable level. ${ }^{2}$ As, harming to patients or healthcare seekers is contradicted with the philosophy of health care, ${ }^{3}$ preventing medical errors is considered as patient safety dimension. Generally, Medical errors are significant and threatening challenges in all countries. ${ }^{4}$

Annual deaths from medication errors account for 7000 out the total number of 48 000-98000 deaths due to drug-induced complications. Medication errors are listed as one of the five medical error categories classified by the American Institute of Medicine. ${ }^{5}$ It is Also, estimated that 55000 medical errors occur each year, resulting 10500 deaths and 23000 physical disabilities. ${ }^{6}$ The results of a study about medication error in 2 teaching hospitals in Boston showed that, $1 \%$ of the incidents are fatal, $12 \%$ life-threatening, 30\% serious and 57\% significant and dangerous. Forty-two percent of classified incident serious were preventable. ${ }^{7}$

In Iran, $8 \%$ of hospital treatments results in medication side effects which is more than the US $(2.4-5.6 \%) .{ }^{8}$ Medication administration is one of the fundamentals of nursing, which requires technique, skill and consideration to the client. Considering, each nurse spends an average of $40 \%$ of the attending time in hospital to administer medication to clients, nurses are at risk for medication errors. ${ }^{9}$ The initial outcome of these errors is an increase of hospital stay and cost and severe harm or even death. ${ }^{10}$ In 1999, Institute of Medicine report on quality of health care, To Error Is Human: Building a Safer Health System called for a more systematic approach to medical errors and outlined the importance of identifying and learning from errors through mandatory and voluntary reporting system. Medication errors have a huge impact on health care system, patients and payers alike. It compromises the confidence of patients on health care system. ${ }^{11}$

Therefore, based on the importance of nursing medication error in Iran, a systematic review has been conducted. The aim of this systematic review is to identify the contributing factor of nurses' medical errors in published Persian articles.

\section{Methods}

In this systematic review, contributing factors of medication errors among nurses were investigated. The search strategy was conducted using the Cochrane seven stage process

Copyright $\odot 2019$ The Author(s). This is an open-access article distributed under the terms of the Creative Commons Attribution License (http:// creativecommons.org/licenses/by/4.0), which permits unrestricted use, distribution, and reproduction in any medium, provided the original work is properly cited. 
including: selecting the year, determining inclusion criteria, finding studies, selecting studies, assessing the quality of studies, extracting the data, analyzing and presenting the findings.

\section{Databases}

In order to review Persian language-literature on medication errors in Iran we searched Persian electronic databases including Google Scholar, IranMedex, SID, Iran doc, Magiran from the published articles in internal journals, congresses, and seminars in a period of 2003-2016.

\section{Search Terms}

The search was carried out using Persian key words including medication errors, Iran, nursing and all possible combination of main including words about medication errors. In addition, the reference list of the identified studies was screened to find additional materials.

\section{Inclusion/Exclusion Criteria}

We considered all types of original studies and conference papers on adults and children that were descriptive studies relevant to nursing conducted in teaching hospitals in Iran. We looked for studies which reported sources of medication errors, reasons for not reporting medication errors, preventive measures of medication errors and most common errors involved in medication errors. The exclusion criteria included: qualitative studies, case reports, review studies, irrelevant to medication errors among nurses and collaborative studies with other healthcare members.

\section{Selection and Information Extraction}

Two authors (A.M. and M.P. as nurses in Iranian health care system) reviewed the articles by following stages: Inclusion and exclusion criteria were assessed both in reading the titles and abstracts of the search. Then, we found all full-texts of the selected articles and the exclusion criteria were also applied to the full-texts. We categorized the results from studies on sources of medication error using framework of factors related to medication errors among nurses.

\section{Results}

A total of 85 articles were selected including: 17 abstracts from seminars, 68 full-text articles, which were reviewed and organized in the EndNote. Thirty-five articles were selected for the final analysis based on the inclusion and exclusion criteria (Figure 1). Firstly, the researcher made a list of all titles and abstracts available in the data bases and assessed them separately to select relevant titles. Then, the relevant papers were entered into the research cycle independently. Finally, extracted data were from papers including information of papers (title and the date of study), characteristics of studies (sample size, control and intervention group) and findings (Table 1). The results were extracted in 3 contributing factors including

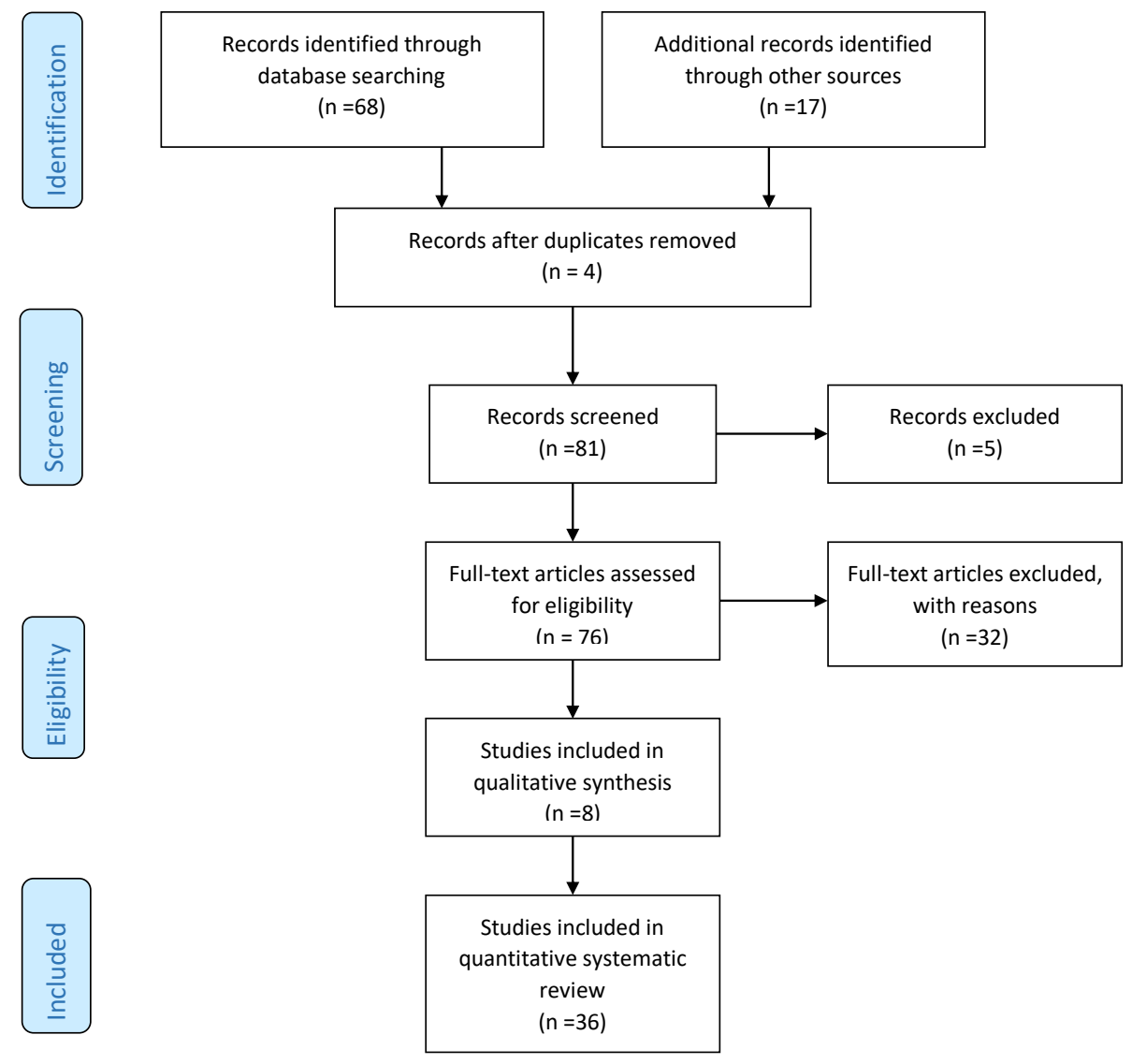

Figure 1. Search Process and Number of Eligible Studies. 
personal factors, organizational factors organizational and personal factors.

\section{Discussion}

This systematic review of Persian articles in Iran indicates that, the following 3 main factors contribute to the occurrence of medication errors among nurses including organizational factors, personal factors and organizational and personal factors.

\section{Organizational Factors}

Fourteen studies were found about barriers to reporting in organization, that 12 studies in nurses and 2 studies in nursing students: In studies conducted on nurses in Tehran, Lorestan, Tabriz (2 studies), Bushehr, Neyshabur, Khorramabad, Isfahan, Urmia and Ahvaz result showed that, barriers to reporting in organization are categorized into 3 domains: 1. managerial factors, 2. Reporting and 3. Consequences of reporting. In

Table 1. Characteristics of Studies on Medication Error Included in Our Final Review With Their Most Frequent Topics Covered

\begin{tabular}{lll}
\hline Author/Date & $\begin{array}{l}\text { Sample Size } \\
\text { Population }\end{array}$ & Results \\
\hline Jolaee et $\mathrm{al}^{4}{ }^{4} 2014$ & 300 Nurses & $\begin{array}{l}\text { The mean of medication errors occurrence for each nurse was } 15 / 11 \text { over } 3 \text { months, and the score of professional } \\
\text { commitment was } 86 \text { (high level of professional commitment). There was no significant relationship between } \\
\text { professional commitment and the rate of medication error }(P<0.320) .\end{array}$
\end{tabular}

Ebrahimpour et al, ${ }^{31} \quad 150$ Nurses
2014

Hesari et al,,$^{14} 2014$ Nurses

Mohammad Nejad et 94 nurses

$\mathrm{al}^{12} 2014$

Pazokian et al, ${ }^{33} 2013 \quad 150$ nurses

Census,

Heidari et al, ${ }^{24} 2014 \quad$ Nursing

students

Seidi and Zartosht, ${ }^{17}$

2012

156 Nurses

Salavati et al, ${ }^{18} 2012 \quad 71$ nurses

Bijani et al, ${ }^{44} 2012 \quad 80$ nurses

Musarezaie et al, ${ }^{9} 2012$

280 nurses

Shams et al, ${ }^{43} 2011 \quad 350$ nurses

Hosseinzadeh et al, ${ }^{13}$

2012

Ebrahimi and

Abdollahi, ${ }^{26} 2012$

300 patients

Rahimi et al, ${ }^{42} 2012$

100 nurses
The most common type of medication error was medication administration to the wrong patient. Antibiotics were the most frequent medication error $(67 \%)$. The reasons of nurses' medication errors were factor such as inaccuracy $(41 \%)$, busy ward $(13.1 \%)$ and illegible hand writing $(11.5 \%)$.

The most important causes of medication error include nursing shortage, fatigue due to extra work, and work overload. The most important causes of lack of reporting include: authorities' focusing on person who made the mistake with no consideration of other contributing factors to error, fear of legal issues and lack of clarity in defining medication error.

The results showed that $72 \%$ of nurses did not reported occurred medication errors. The most common type of error was the rate of infusion (33.3\%). The most important causes of medication errors were nursing shortage $(47.6 \%)$ and lack of pharmacology knowledge $(30.9 \%)$. The most frequent causes of lack of reporting were fear of its consequences and insignificance of reporting error.

The results showed that among personal and organisational factors affecting on medication error, nurse-physician communication and work commitment were affecting variables with learning atmosphere in the medication error model.

$27.5 \%$ of the sample had medication error. The most frequent errors were related to calculating drug dosage and intra venous drugs. $50 \%$ of students reported their error. The most important reasons of lack of reporting include the following: fear of low score, fear of instructor's reaction, lack of knowledge about reporting process, knowledge deficit and believing in insignificance of the error.

The most frequent errors were occurred during transferring medical order from record to kardex (73.9\%), prescribing incorrect dosage by physician and incorrect setting of infusion devices $(64.1 \%) .45 \%$ of nurses reported medication errors, and the reasons of lack of reporting were knowledge deficit about reporting and forgetting the error (59.8\%).

The most important reasons for medication errors were the following: fatigue due to extra work, shortage of nurses, many critically ill patients, long working hours, high nursing workload in ward and performing other tasks concurrent with medication administration. The most important reason of lack of reporting medication errors was managerial factors $4 / 12$.

The most important reasons of medication errors were fatigue due to work, nursing shortage, long working hours, and high nursing workload in units.

$20 \%$ of the sample had medication errors. The mean of medication error was 11 cases over 3 months, and reporting of error was 1.5 case for each nurse. The most common reported errors include incorrect infusion rate and incorrect drug dosage. The most common reason of lack of reporting was fear of its consequences; legal issues had the highest frequency.

The mean of medication errors and reporting were 28.9 and 14.4, respectively. Data analysis also showed that there was a significant relationship between medication errors and nurses' age: the most frequent error was in the age group 20-30 $(P=0.035)$. There was a significant relationship between working hours $(P=0.023)$ and participating in continuing education $(P=0.033)$ and medication errors and its reporting $(P=0.0001)$.

The most important reasons of medication error were fatigue due to extra work $95.5 \%$, nurses' shortage $85 \%$ and high workload in the unit $82.5 \%$. The most important reasons for lack of reporting medication errors include: legal issues $73.5 \%$, focusing on the person making the mistake with no consideration of other factors $76 \%$ and lack of clarity of defining medication error $44.5 \%$.

The results showed that $76 \%$ of patients did not know the name of their medications, $31 \%$ were not able to distinguish cardiac drugs from other drugs, $20 \%$ did not know the dosage and time of their medications. Only $13.3 \%$ of patients received the information from pharmacies, and $19.3 \%$ had more than 48 hours delay in providing medications.

All participating nurses had a history of medication errors since 1 year ago. The most common medication errors include: the wrong patient $26 \%$, type of drug $19 \%$, drug administration $9 \%$, dosage and time of the drug $23 \%$. 
Table 1. Continued

\begin{tabular}{lll}
\hline Author/Date & $\begin{array}{l}\text { Sample Size } \\
\text { Population }\end{array}$ & Results \\
\hline Mirzaei et al, ${ }^{20} 2012$ & 96 nurses & $\begin{array}{l}\text { The prevalence of medication error was } 79.2 \% \text { among nurses. The most frequent errors include administering } \\
\text { multiple drugs simultaneously and administering medication earlier or later than the due. The rate of reporting } \\
\text { medication errors was } 14 \% . \text { The barriers to reporting classified into } 3 \text { domains: managerial, consequences of } \\
\text { reporting and reporting. }\end{array}$
\end{tabular}
Parish et al, ${ }^{19} 2012$ nurses $\quad$ reporting, managerial factors, reporting factors were barriers to reporting, and fear of consequences of reporting was

The results showed that $53 \%$ of nurses have experienced medication errors. Three domains of the consequence of higher than other domains.

$\begin{array}{lll}\text { Zaman Zade et al, }{ }^{22} 2011 & \begin{array}{l}\text { The rate of reporting medications errors was much lower than the number of errors. The most important barriers to } \\ \text { reporting include: faulting the person instead of the system, concern about the consequence of reporting, and fear of } \\ \text { reprimand for reporting. }\end{array} \\ \begin{array}{l}\text { Ebrahimi Rigi Tanha et } \\ \mathrm{al}^{38} 2011\end{array} & \begin{array}{l}54 \text { nursing } \\ \text { students }\end{array} & \begin{array}{l}\text { The most frequent errors occurred during drug administration } 87.3 \%, \text { and the most common type of reported } \\ \text { medication errors was antibiotics, which was administered sooner or later than the due. }\end{array} \\ \text { Bastani et al, }{ }^{21} 2011 & \begin{array}{l}\text { Census of } \\ \text { nurses }\end{array} & \begin{array}{l}\text { Factors including lack of recording and reporting system in hospital, insignificance of reporting medication error for } \\ \text { authorities, lack of appropriate feedback and lack of clear definition of medication errors were the most important } \\ \text { contributing factors to lack of reporting error. }\end{array}\end{array}$

Ghasemi, 50 nurses

The results showed that the most important contributing factors to medication error include: similarities in the name of drugs, incorrect reading of the name of drug in the kardex, and pharmacological knowledge deficit. $\begin{array}{ll}\text { Taheri et al, }{ }^{6} 2011 & \begin{array}{l}\text { The results showed that the most important factors contributing to medication errors including fatigue due to extra } \\ \text { work } 63.9 \% \text {, inadequate time } 61.9 \% \text {, nursing shortage } 58.1 \% \text {, lack of pharmacological knowledge } 48.9 \%, \text { high } \\ \text { workload in ward } 45.4 \% \text {, illegibility of physicians' handwritten in records } 40.2 \% .\end{array} \\ & \begin{array}{l}\text { The results showed that } 73.43 \% \text { of nurses had medication errors. } 42.55 \% \text { reported the impeding medication error. } \\ \text { Cheraghi et al, }{ }^{35} 2011 \text { nurses }\end{array} \quad \begin{array}{l}57.44 \% \text { had not reported any impending or occurred error. The most common types of medication errors were } \\ \text { infusion rate and drug dosage due to using abbreviated names and similarities in drug names. The most important } \\ \text { reason of medication errors was pharmacological knowledge deficit. }\end{array}\end{array}$

$\begin{array}{ll}\text { Azemian et al, }{ }^{15} 2011 & \text { The most important barrier to lack of reporting include: mangers' focusing on the person making the mistake with no } \\ \text { consideration of other reasons }(74.6 \%) \text {, fear of legal issues }(74.3 \%) \text {. The least important barrier to lack of reporting }\end{array}$

was insignificance of error from nurses' perspective. Hajibabaiee et al, ${ }^{28} 2011286$ nurses multiple oral drugs. Nurses who had not participated in courses about drug administration had higher rates of medication errors.

Jolaee et al, ${ }^{34} 2009 \quad 286$ nurses The mean of medication errors was 19.5 case, and the mean of reporting was 1.3. The rate of medication errors was higher in harder working condition, but reporting error had no change in this condition.
400 nurse, $\quad 49.9 \%$ of personnel experienced medication errors. The most frequent errors were drug dosage ( $37.7 \%)$ and type of Zahmatkeshan et al, ${ }^{40} \quad$ midwives drug $(27.7 \%) .73 .3 \%$ of them reported error, and the most frequent reason of lack of reporting was fear of authorities' $2010 \quad$ and assistive and assistive reaction. Medicine-related factors (illegible handwriting) $24.94 \%$ and nurse-related factors were $24.38 \%$. The personnel most common reasons of medication errors include: interpersonal relationship, inappropriate ward environment, knowledge and experience deficit and stressful factors.

\begin{tabular}{|c|c|c|}
\hline Koohestani et al, ${ }^{10} 2008$ & $\begin{array}{l}76 \text { nursing } \\
\text { students }\end{array}$ & $\begin{array}{l}\text { The results showed that medication errors occurred in } 17.1 \% \text { of students, and } 43.42 \% \text { of students had impending } \\
\text { medication errors. } 39.47 \% \text { of students did not report any occurred and impending error. The most common reporte } \\
\text { medication errors were related to incorrect dosage and the most common reason was poor pharmacological } \\
\text { knowledge. }\end{array}$ \\
\hline $\begin{array}{l}\text { Koohestani \& } \\
\text { Baghcheghi, }{ }^{23} 2008\end{array}$ & $\begin{array}{l}\text { Census of } \\
\text { nursing } \\
\text { students }\end{array}$ & $75 \%$ of errors were reported by students. Fear domain was the most common reason of lack of reporting. \\
\hline Vali Zade et al, ${ }^{37} 2008$ & $\begin{array}{l}898 \\
\text { hospitalized } \\
\text { patients' } \\
\text { records }\end{array}$ & $\begin{array}{l}\text { In } 74.1 \% \text { of cases necessary recommendation was not written about order administration. In } 47.8 \% \text { of cases the } \\
\text { interval between drugs was not clarified. In } 45.5 \% \text { of cases it was written suspiciously. There was a drug interaction } \\
\text { in } 20.5 \% \text { of medication orders. Nursing reports indicated that } 77.5 \% \text { of precautions related to administering } \\
\text { medication orders were not considered. In } 14.9 \% \text { drug interaction was not considered. In } 14.8 \% \text { drug interval was } \\
\text { not based on physician's order. In } 6.3 \% \text { of cases, medication order was not administered. }\end{array}$ \\
\hline 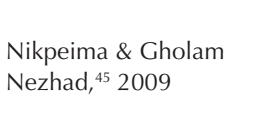 & 100 nurses & $\begin{array}{l}53 \% \text { of the sample has had at least one medication error over their work experience. The most common types } \\
\text { of error include: incorrect dosage, not administering and incorrect time. The most frequent rates of medication } \\
\text { error were in age group } 25-30 \text {, Neonatal and Paediatric wards and in the mooring shift in which there were high } \\
\text { workload, less staff, fatigue and long working hours. }\end{array}$ \\
\hline
\end{tabular}

\begin{tabular}{lll} 
Heidari et al ${ }^{41} 2010$ & $\begin{array}{l}\text { From nurses' perspectives, the most important risk factors include the following: organisational 3.94, personal 3.57, } \\
\text { medication orders 3.55, and environmental factors. The highest means were nurses' workload 4.2, physician's } \\
\text { illegible handwritings 4.18, inability of drug calculation 3.84, expelling pills from package 4.19 from organisation } \\
\text { medication orders, personal and environmental factors, respectively. }\end{array}$ \\
$\begin{array}{l}\text { Baghcheghi \& } \\
\text { Koohestani, }{ }^{27} 2009\end{array}$ & $\begin{array}{l}22 \text { nursing } \\
\text { instructors }\end{array}$ & $\begin{array}{l}50 \% \text { and } 100 \% \text { of instructors observed occurred and impending medication error at least once, respectively. The } \\
\text { most common medication errors among nursing students included: pharmacology knowledge deficit, poor drug } \\
\text { calculation and illegible handwritten in the kardex. }\end{array}$ \\
\hline
\end{tabular}


Table 1. Continued

\begin{tabular}{|c|c|c|}
\hline Author/Date & $\begin{array}{l}\text { Sample Size } \\
\text { Population }\end{array}$ & Results \\
\hline $\begin{array}{l}\text { Koohestani \& } \\
\text { Baghcheghi, }{ }^{36} 2007\end{array}$ & $\begin{array}{l}60 \text { nursing } \\
\text { students }\end{array}$ & $\begin{array}{l}\text { The error occurred in } 10 \% \text { of research units. } 41.66 \% \text { reported impending medication error. } 48.34 \% \text { did not report } \\
\text { any impending and occurred medication error. The most common type of medication error included: incorrect drug } \\
\text { calculation, lack of attention to drug dosage in the medication card and poor pharmacological knowledge. }\end{array}$ \\
\hline $\begin{array}{l}\text { Baghcheghi \& } \\
\text { Koohestani, }{ }^{29} 2008\end{array}$ & $\begin{array}{l}52 \text { nursing } \\
\text { students }\end{array}$ & $\begin{array}{l}153 \text { errors out of } 372 \text { observed cases were identified. The most common error in the preparation phase was error in } \\
\text { solution and soluting drug }(2.6 \%) \text {, and the most common error in the infusion phase was inappropriate infusion rate } \\
(11.5 \%) \text {. The most common reason of errors was poor pharmacology }(18.95 \%) \text {. }\end{array}$ \\
\hline Soozani et al, ${ }^{39} 2007$ & 40 nurses & $\begin{array}{l}\text { The results showed that the most important factors contributing to medication errors included: fatigue due to extra } \\
\text { work }(66.7 \%) \text {, nursing shortage related to patients }(59 \%) \text {, nurse' psychological problems }(48.7 \%) \text {, illegibility of } \\
\text { physician's order }(42.5 \%) \text {, and lack of time }(42.1 \%) \text {. }\end{array}$ \\
\hline Ghasemi et al, ${ }^{32} 2008$ & 86 nurses & $\begin{array}{l}\text { The results showed that important reasons for medication errors included: nursing shortage }(100 \%) \text {, lots of shifts } \\
\text { and night shift }(83.7 \%) \text {, personal problems }(79.9 \%) \text {, chaos ward }(79.9 \%) \text {, inappropriate environment }(73.3 \%) \text {. The } \\
\text { reasons of lack of reporting included: fear of reprimand }(88.4 \%) \text {, insignificance of medication errors }(57 \%) \text {, lack } \\
\text { of support from nursing authorities }(51) \text {. The most important way to prevent medication error was increasing the } \\
\text { number of staff related to the number of patients }(98.8 \%) \text {, personnel education }(96.5 \%) \text { and giving information about } \\
\text { new drugs }(96.8 \%) \text {. }\end{array}$ \\
\hline
\end{tabular}

managerial domain, managers' inappropriate reactions to reporting medication errors and nursing authorities' lack of support; in reporting domain, insignificance of nurses' reporting of medication errors; in the consequence of reporting, fear and concern of the effects of these errors on financial and legal issues were stated. In a study conducted in Shohadaye Tajrish hospital in Tehran, the main factor of lack of reporting was found to be lack of recording and reporting system. While, in studies conducted in Bushehr, Neyshabur, Tabriz and Ahvaz, nursing manages' focusing on the personal mistake with no consideration of other contributing factors. In other 2 studies which were conducted in Neyshabur, Tabriz, Tehran, Bushehr, Ahvaz and Lorestan, lack of clarity about medication errors and insignificancy were reported as factors contributing to lack of reporting. Furthermore, in a study carried out in Mashhad regarding barriers to reporting errors, knowledge deficit about reporting and forgetting reporting were identified. ${ }^{12-22}$ In addition, the results of 2 conducted studies on nursing students in Rafsanjan and Arak showed that, the main reason of lack of reporting medication error is fear of the consequences of report in organization. Another conducted research in Arak demonstrated that, the mean of reporting process domain was less than other studies, which is probably due to difference of the reporting process between nurses and nursing students. Besides, students had fear of evaluation, instructor's reaction and effect on teaching process. While, on the other hand, in the study conducted in Rafsanjan, lack of justification among instructors about how to handle students with mistakes contributed to increasing reporting medication errors. ${ }^{23,24}$

In this review, 3 studies were carried out on nurses, nursing students, and patients regarding prevention of medication errors in Arak, Khorramabad, and Mashhad and Tehran cities (2 studies). Education was reported as one of the preventive measures in organization. ${ }^{25-27}$ Three studies were found on medication errors and organizational factors in Tehran and Kermanshah. In a study conducted in Kermanshah, in addition to examined the rate of reporting error also examined the rate of error. In studies done in Tehran, the mean of errors was examined over 3 months. The findings of both studies were inconsistent. In both studies, the most frequent error was administering multiple drugs simultaneously, which was inconsistent with the study conducted in Kermanshah. ${ }^{20,28}$ Other study assessed professional commitment and medication error. However, this high rate of commitment had no effect on medication error. While, in a study conducted in 2008, gender and passing educational course about drug administration were examined which indicated the most frequent medication errors were related to men and people who do not participate in the educational course. In present studies, the mean of error in Iran was higher than other countries, which is probably due to particular condition in Iran including staff shortage relate to the standards in healthcare services, high ratio of patient to nurse and nurse' workload. In addition to personal factors, an important section of these factors is related to healthcare management system. ${ }^{4}$

\section{Personal Factor}

Five studies on surveys of medication errors were found; 3 studies were conducted on nursing students and 2 studies on nurses. The results of 3 studies on nursing students in Tehran, Kermanshah and Arak indicated that, medication errors are observed in all stages of entering in kardex, medication preparation, drug diluting and administration to patients. In a study carried out in Tehran, the main reason of error was reported incorrect entering of drug in kardex and lack of attention to drug dosage in the kardex or record, which is consistent with the study conducted in Kermanshah. In a study was performed in Kermanshah stress during medication administration has also been identified as a reason, while in the study conducted in Arak pharmacological knowledge deficit was identified as the main reason of error. ${ }^{12,29,30}$

In addition, the results of 2 studies that were conducted on nurses in Shiraz and Isfahan showed that, the most common error in Isfahan was wrong patient, and antibiotics were the most frequent error. While in the study carried out in Shiraz, the most frequent errors were the number of medications more than 3 drugs and illegible drug order. Some medication 
errors do not, mentioned, due to managers and instructors' negative reactions. However, mangers and instructor must know that clarifying the error is a type of accountability to the error from healthcare members, and considered as nursing task that result in planning. On the other hand, hiding errors could result in some problems ethical and therapeutic decision making. ${ }^{31,32}$

\section{Organizational and Personal Factors}

Pazokian et $\mathrm{al}^{33}$ found that personal and organizational factors influence on medication errors. Based on the medication error model, learning atmosphere was considered as a moderating variable in preventing medication error, which had significant relationship with organizational variables including physician-nurse interaction and work commitment. However, other personal factors including age and work experience had no effect on medication errors and moderating factor. Furthermore, Jolaee et $\mathrm{al}^{34}$ found that the rate of medication errors is associated with working condition, so that the possibility of medication errors in appropriate working condition are less than inappropriate working condition. Altogether, these studies indicated that, assessing and moderating of nursing working condition provide a context for reducing medication errors. As a result, creating appropriate working system with working condition improvement could lead to decreasing medication errors.

Four studies were conducted including 3 studies in critical care units and one study in pediatrics ward. The results of studies conducted in critical care units - one study conducted on students and the other on nurses - showed that, the most common reason of medication errors among nurses and nursing students include incorrect drug calculation, incorrect dosage and similarities in the name of drugs such as Dopamine and Dobutamine. ${ }^{35}$ Moreover, in the study conducted on nursing students, heparin was the most common drug that was not calculated correctly. ${ }^{35}$ Since, drugs used in critical care units are very sensitive, it is necessary to promote knowledge and skills of pharmacology and drug calculation through continuing education particularly for nurses and nursing students..$^{36}$ On the contrary, the results of a study conducted on nurses indicated that, factors related to working condition and rewriting of medication orders had the major role in medication errors. ${ }^{6,35-37}$ The results of another study carried out in pediatrics ward showed that, the most frequent errors among nurses are lack of considering drug precautions and lack of attention to drug interactions. ${ }^{37}$

Eleven studies and 3 seminars were extracted on factors contributing to medication error. Though, these studies have examined a variety of contributing factors including working condition, fatigue, workload etc., and 2 main factors of personal and contribute to medication errors that have been found in all studies. Three studies address the prevalence of medication errors in addition to contributing factors. The most common errors include incorrect dosage, not administering and incorrect time which can result from lack of pharmacological knowledge among nurses and workload and forgetfulness. On the other hand, incorrect time was administration sooner or later than the due which have not been considered medication error from nurses' perspectives. However, considering five Rs, correct time is also one of the factors in preventing medication error. ${ }^{10,21,38-45}$

In this review, 4 review studies on medication errors found areas of medication error (reasons of medication errors and preventing, ethical response to error, contributing factors to medication errors). ${ }^{46-49}$

In general, the results of this review on medication errors in Iran Indicated that, no factors can result in medication error separately. Most medication errors result from multiple and interactive factors. The results of present study indicate that, main factor in all medication errors are personal and organizational factors. ${ }^{34}$ since personal factors including fatigue, personal problems, distraction and forgetfulness etc., are unavoidable, most studies have focused on organizational factors. There are many debates about organizational variables affecting on patients safety. Clinicians use organizational approach for preventing medication errors. There are many models about patient safety; however, Reason's model of human errors is one of the models that are commonly used based on prevention-based framework. According to this model, human errors are classified into 2 personal and systemic factors. ${ }^{50}$ In addition, According to systemic approach, errors are expected even in the best organizations. Most problems in organizations are complicated, ill-defined and interactive with some factors. Besides, there are important facts about human errors that have been overlooked. Firstly, best people could do the worst errors. Secondly, errors have few returning pattern in addition to randomization. ${ }^{51}$

\section{Conclusions}

Our results showed that,in Iran a variety of measures are used to reduce errors, but many solutions have largely ignored the cultural and organizational approach and should try to adjust and learn from medication errors as it will slightly improve environmental conditions. Adverse working conditions including high level of workload, chaos situation and staff shortage increase medication error. The rate of medication errors could be reduced through correct planning and management, developing positive learning climate without punishment and reprimand and continuing education. Altogether, it should be implemented not only in main centers including the Ministry of Health and Medical Education and Health Science Universities but also in the lowest levels including hospitals and clinical centers.

\section{Authors' Contributions}

AM: assistance in study design and statistical analysis, data acquisition, and manuscript drafting; MP: administrative, technical, and material support; study supervision; and critical revision of the manuscript for important intellectual content and drafting of the manuscript.

\section{Conflict of Interest Disclosures}

The authors declare they have no conflicts of interest.

\section{Acknowledgments}

This article was extracted from masters' thesis of the Faculty 
of Nursing. It was funded by the Health Science Research Centre at the Baqiyatallah University of Medical Sciences.

\section{References}

1. Hov R, Hedelin B, Athlin E. Good nursing care to ICU patients on the edge of life. Intensive Crit Care Nurs. 2007;23(6):331-341. doi:10.1016/j.iccn.2007.03.006.

2. Rozich JD, Haraden CR, Resar RK. Adverse drug event trigger tool: a practical methodology for measuring medication related harm. Qual Saf Health Care. 2003;12(3):194-200. doi:10.1136/ qhc.12.3.194.

3. Marin HF. Improving patient safety with technology. Int J Med Inform. 2004;73(7-8):543-546.doi:10.1016/j.ijmedinf.2004.05.006.

4. Jolaee S, Shali M, Hooshmand A, Haghani H. The relationship between incidence of medication errors and nurse's professional commitment. Medical Ethics Journal. 2014;8(28):101-119. [Persian].

5. Grissinger MC, Kelly K. Reducing the risk of medication errors in women. J Womens Health (Larchmt). 2005;14(1):61-67. doi:10.1089/jwh.2005.14.61.

6. Tahery N, Rashidi Avandi M, Hojjati H, Gorgian Z. Factors affecting harmful medication errors viewed by nurses employed by the hospitals affiliated to Abadan University of Medical Sciences, 2011. Education \& Ethic In Nursing. 2013;2(3):47-52. [Persian].

7. Bates DW. Using information technology to reduce rates of medication errors in hospitals. BMJ. 2000;320(7237):788-791. doi:10.1136/bmj.320.7237.788.

8. Moghaddasi H, Sheikhtaheri A, Hashemi N. Reducing medication errors:Role of computerized physician order entry system. Journal of Health Administration. 2007;10(27):57-67. [Persian].

9. Musarezaie A, Momeni Ghale Ghasemi T, Zargham-Boroujeni A, Haj-Salhehi E. Survey of the medication errors and refusal to report medication errors from the viewpoints of nurses in hospitals affiliated to Isfahan university of medical sciences, Iran. Health System Research. 2013;9(1):76-85. [Persian].

10. Koohestani HR, Baghcheghi N, khosravi SH. Frequency, type and causes of medication errors in student nurses. Iran Journal of Nursing. 2008;21(53):17-27. [Persian].

11. Institute of Medicine Committee on Quality of Health Care in America. In: Kohn LT, Corrigan JM, Donaldson MS, eds. To Err is Human: Building a Safer Health System. Washington (DC): National Academies Press (US); 1999.

12. Mohammad NejadE, Ehsani SR, SalariA, SajjadiA, Hajiesmaeelpour A. Refusal in reporting medication errors from the perspective of nurses in emergency ward. Journal of Research Development in Nursing \& Midwifery. 2013;10(1):61-68. [Persian].

13. Hosseinzadeh M, Ezate Aghajari P, Mahdavi N. Reasons of nurses' medication errors and persepectives of nurses on barriers of error reporting. Journal of Hayat. 2012;18(2):66-75. [Persian].

14. Hesari B, Ghodsi H, Hoseinabadi M, Chenarani H, Ghodsi A. A survey of nurses' perceptions of the causes of medication errors and barriers to reporting in hospitals affiliated to Neyshabur university of medical sciences, Iran. Journal of Kerman University of Medical Sciences. 2014;21(1):105-111. [Persian].

15. Azemian A, Vahed Parast H, Mirzaee K. Examine the barriers to reporting errors in nursing from the perspective of nurses working in teaching hospitals of Bushehr in 2010. Tose'e Amozesh Pezeshki. 2011;4:210-212. [Persian].

16. Heydari H, Kamran A, Pirzadeh A. Assessment of Nurses' Perceived Barriers and Behaviors to Reporting Medication Errors in Hospitals of Lorestan University of Medical Sciences, Iran. Health System Research. 2012;8(5):806-813. [Persian].

17. Seidi M, Zardosht R. Survey of Nurses' Viewpoints on Causes of Medicinal Errors and Barriers to Reporting in Pediatric Units in Hospitals of Mashhad University of Medical Sciences. Journal of Fasa University of Medical Sciences. 2012;2(3):142-147. [Persian].

18. Salavati S, Hatamvand F, Tabesh H, Salehi Nasab M. Nurses' Perspectives on Causes of Medication Errors and Non- Reporting at ED. Iran Journal of Nursing. 2012;25(79):72-83. [Persian].

19. Parish B, Omidi M, Hasan Nezhad N, et al. Nnursing staff view of causes and contributing factors to the lack of reporting of medication errors in the Madani hospital. First Student Congress of Clinical Governance and Continuous Quality Improvement; Tabriz University of Medical Sciences; 2012. [Persian].

20. Mirzaei M, Khatony A, Safari Faramani R, Sepahvand E. Prevalence, Types of Medication errors and Barriers to Reporting Errors by Nurses in an Educational Hospital in Kermanshah. Journal of Hayat. 2013;19(3):28-37. [Persian].

21. Bastani P, Kalhor R. Assessing factors affecting the lack of nurses reporting medication errors: study in Shohada Hospital; First Student Congress of Clinical Governance and Continuous Quality Improvement. Tabriz University of Medical Sciences. 2011. [Persian].

22. Zamanzadeh V, Zarezadeh $\mathrm{Y}$, Bayazidi S, et al. The report errors barriers and facilitators among nurses. First Student Congress of Clinical Governance and Continuous Quality Improvement. Tabriz University of Medical Sciences. 2011. [Persian].

23. Koohestani H, Baghcheghi N. Refusal in Reporting Medication Errors from the Viewpoints of Nursing Students in Arak University of Medical Sciences. Iranian Journal of Medical Education. 2009;8(2):285-292. [Persian].

24. Heidari S, Shahabinejad M, Soltani A, Abdoli F. Rate and type of medication errors and factors in preventing the report of them in the nursing students. Community Health Journal. 2013;2-3(7):4855. [Persian].

25. Ghasemi F, Valizadeh F, Moemen Nasab M. Analyzing the knowledge and attitude of nurses regarding medication error and its prophylactic ways in educational and therapeutic hospitals of Khorramabad. Yafteh. 2009;10(2):55-63. [Persian].

26. Ebrahimi M, Abdollahi A. Preventable Medication Errors in High Risk Cardiac Patients; A call for Systematic Reconsideration for Social Health. Medical Journal of Mashhad University of Medical Sciences. 2012;55(4):201-205. [Persian].

27. Baghcheghi $\mathrm{N}$, Koohestani $\mathrm{H}$. The Comments of nursing educators about reasons and reduction strategies of medication errors in nursing students in Arak University of Medical Sciences, 2008. Arak Medical University Journal. 2010;12(4 Suppl 1):1-8. [Persian].

28. Hajibabaiee F, Jolaee $S$, Peyravi H, Haghani $H$. The relationship of medication errors among nurses with some organizational and demographic characteristics. Iranian Journal of Nursing Research. 2011;6(20):83-92. [Persian].

29. Baghcheghi N, Koohestani H. Nursing students' errors in preparation and administration of intravenous drugs. Strides in Development of Medical Education. 2008;5(1):43-49. [Persian].

30. Abasi $P$, Timareh $M$, et al. The incidence of medication errors. Ofogh. 2011;4:10-12. [Persian].

31. Ebrahimpour F, Shahrokhi A, Ghodousi A. Patients' safety and nurses' medication administration errors. Iranian Journal of Forensic Medicine. 2014;20(1):401-408. [Persian].

32. Ghasemi M. The amount and type of medication errors of nursing in Shiraz Heart Center summer of 2011. First Student Congress of Clinical Governance and Continuous Quality Improvement. Tabriz University of Medical Sciences. 2011. [Persian].

33. Pazokian M, Zaghari Tafreshi M, Rassouli M, Zayeri F. Testing Nurses' Medication Errors Model based on Reason Human Error Model. Iran Journal of Nursing. 2013;26(85):1-14. [Persian].

34. Jolaee S, Hajibabaee F, Peyravi H, Haghani H. Nursing medication errors and its relationship with work condition in Iran University of Medical Sciences. Journal of Medical Ethics and History of Medicine. 2009;3(1):65-76. [Persian].

35. Cheraghi MA, Nikbakhat Nasabadi AR, Mohammad Nejad E, Salari A, Ehsani Kouhi Kheyli SR. Medication Errors Among Nurses in Intensive Care Units (ICU). Journal of Mazandaran University of Medical Sciences. 2012;21(1):115-119. [Persian].

36. Koohestani $\mathrm{H}$, Baghcheghi $\mathrm{N}$. Investigation medication errors of nursing students in Cardiac. Iranian Journal of Forensic Medicine. 2008;13(4):249-255. [Persian]. 
37. Valizadeh F, Ghasemi SF, Najafi S, Delfan B, Mohsenzadeh A. Errors in medication orders and the nursing staff's reports in medical notes of children. Iran J Pediatr. 2008;18(Suppl 1):33-40. [Persian].

38. Ebrahimi Rigi Tanha Z, Baghaei R, Feizi A. A survey of frequency and type of medical errors done by nursing students of Urmia Medical Sciences University in 2010. Journal of Urmia Nursing and Midwifery Faculty. 2012;10(2):139-144. [Persian].

39. Soozani A, Bagheri H, Pourheydari M. Survey nurse's view about factors affects medication errors in different care units of Imam Hossein hospital in Shahroud. Knowledge and Health. 2007;2(3):8-13. [Persian].

40. Zahmatkeshan N, Bagherzadeh R, Mirzaie K. An observational study to evaluate the medication errors by nursing staff working in Bushehr Medical Centers during one year interval (2006-2007). Iranian South Medical Journal. 2010;13(3):201-206. [Persian].

41. Heidari S, Negahban T, Fatehi Z. Assessment of nurses opinions regarding risk factors of patient safety and medication errors and role of environmental factors, among Rafsanjan university hospitals during 2007. Community Health Journal. 2010;4(34):57-64. [Persian].

42. Rahimi F, Ahangarzadeh Rezaei S, Baghaei R, Faezi A. Factors affecting the incidence of medication errors in nursing staff of Besat Hospital in Sanandaj City in 2011. Scientific Journal of Nursing, Midwifery and Paramedical Faculty. 2016;1(3):12-17. doi:10.29252/sjnmp.1.3.2. [Persian].

43. Shams S, Bagherieh F, Feizi A, Baghaei R, Hashemlo L. Frequency of medication errors and its reporting according to self-report by nurses in hospitals of Khoy city. Journal of Urmia Nursing and Midwifery Faculty. 2012;10(5):721-726. [Persian].

44. Bijani M, Kouhpayeh SA, Abadi R, Tavacool Z. Effective factors on the Incidence of medication errors from the nursing staff perspective in various department of Fasa Hospital. Journal of Fasa University of Medical Sciences. 2013;3(1):88-93. [Persian].

45. Nikpeima N, Gholam Nezhad H. Nursing perspective causes of medication errors. Journal of Nursing and Midwifery Martyr Beheshti. 2009;19:18-24. [Persian].

46. Yaghoubi M, Salehi-nia H, Charkht-Gorgij E, et al. Investigating the causes of medication errors in nurses, and strategies to prevent it. Beyhagh. 2015;18(2):9-21. [Persian].

47. Hashemi F. Ethical response to nursing error. Journal of Medical Ethics and History of Medicine. 2008;1(4):31-46. [Persian].

48. Bahamian F, Noori S. Study of factors affecting medication errors. First Student Congress of Clinical Governance and Continuous Quality Improvement. Tabriz University of Medical Sciences. 2011. [Persian].

49. Zakki N, Asadollahi A, Nisari N, et al. Factor affecting medication errors in nurses. First Student Congress of Clinical Governance and Continuous Quality Improvement. Tabriz University of Medical Sciences. 2011. [Persian].

50. Reason J. Human error: models and management. BMJ. 2000;320(7237):768-770. doi:10.1136/bmj.320.7237.768.

51. Leape LL, Brennan TA, Laird N, et al. The nature of adverse events in hospitalized patients. Results of the Harvard Medical Practice Study II. N Engl J Med. 1991;324(6):377-384. doi:10.1056/ nejm199102073240605. 